\title{
HOW HELPFUL THE WRITERS ARE: A CORPUS-ASSISTED DISCOURSE STUDY OF ONLINE REVIEWS OF TOURIST ATTRACTIONS
}

\author{
Rika Mutiara \\ Esa Unggul University \\ rika.mutiara@esaunggul.ac.id \\ DOI: https://doi.org/10.24071/ijhs.2018.010206
}

received 11 October 2017; revised 31 January 2018; accepted 21 February 2017

\begin{abstract}
The use of corpus methods that combines both quantitative and qualitative aspects has benefited the field of discourse analysis. It is a corpus-assisted discourse study. The study focuses on the ways the writers of online reviews of tourist attractions in TripAdvisor website interact and how they position themselves and the readers. The study employed Lextutor online to get the keywords and Antconc to find the collocations and scrutinize the concordance lines. In the interaction, the writers evaluated the tourist attractions, gave advice and instructions, recounted, reported what the others said, thanked, and encouraged the readers to imagine. The writers tried to provide the information as much as possible and put themselves as the ones that have wider knowledge than the readers. They did it to help the readers make the right decision and anticipate particular conditions. A particular language structure such as prepositional phrases becomes the salient features of this text type.
\end{abstract}

Keywords: corpus, discourse, review, phraseology

\section{Introduction}

The use of the internet as a media of communication enables people to spread their writings fast. Some websites provide opportunities to review particular things such as books, movies, hotels, tourist attractions, etc. Such writing can be called as an online review. Online review is considered as a new way of communication as a result of technology development. This study deals with discourse analysis of online reviews.

Doing discourse analysis gives the opportunities to see how the writers treat the readers, evoke particular feelings and attitude, and construct the way of thought (Gee, 2011). Strauss and Feiz (2014) pointed out several items to be observed in the discourse namely verb, adjective, adverb, and deixis. Through the verbs, power, intention, and spontaneousness can be known. In studying the adjectives, essential details can be revealed. In observing the adverb, writers' attitudes and point of view can be uncovered. In examining the deixis, the way the writers get readers' attention can be seen. 
Discourse can be studied by applying corpus methods. The benefit is to see meanings that are difficult to see through non-corpus methods (Partington, Duguid, \& Taylor, 2010). It, moreover, enables the researchers to study the language patterns. The existence of such patterns reveals elements that become the features of the texts. Baker (2004) suggested studying concordance lines manually besides observing the keywords and the collocations to see the patterns in the texts. It helps the researchers to shed light on the use of the patterns. Those patterns might form larger language chunks (n-gram) such as three and four words lexical bundles. Lexical bundles were defined as "basic building blocks for constructing spoken and written discourse" (Biber \& Conrad, 1999, p. 188).

There are several elements that can be the starting points of discourse analysis. One of them is a keyword. A keyword is an important element in discourse. To get keywords, there must be two corpora. One corpus plays a role as a study corpus and the other functions as a reference corpus. Statistical analysis counts what words become the keywords. According to Scott and Tribble (2006, p.73), keyness is "a quality words may have in a given text or set of texts, suggesting that they are important, [that] they reflect what the text is really about". Studying concordance lines of those words might reveal writers' main intention in the texts.

In some studies, particular words that are considered as the main topics of the corpora were set up as the starting point. One of the studies was done by Baker, Gabrielatos, Khosravinik, Krzyzanowski, McEnery, and Wodak (2008). They conducted collocation analysis and concordance study of the selected words. The texts discussed the issues of refugee, asylum seeker, immigrant, and migrant in the UK newspapers. It discovered the topics related to the issues and the strategies on how the issues were presented. It led to the study of semantic preference and semantic prosody. Besides, it explored the differences that exist in each type of newspapers. Text comparison also can be done by using this technique. Jaworska \& Krishnamurthy (2012) compared how feminism is represented in the UK and German society based on newspapers corpora through collocation analysis. The collocates cover both content and function words. It did not examine the patterns that tend to occur with the keywords. In the UK, it was seen as socio-political movement while in Germany, it was considered as a part of intellectual.

In using selected word, the word may have two different word class (Hamilton, Adolphs, \& Nerlich, 2007). Risk as a noun and a verb was chosen because it was considered as a word that does not have clear meaning. The contexts of the words were categorized into health, finance, interpersonal relation, and others. The occurrences of the words were split into intimate, socio-cultural, professional, transactional, and pedagogic categories. It revealed what the language users conveyed in each category.

All studies mentioned above used non-compound words as the starting points of analysis. Koteyko (2012) focused on carbon compound. The word carbon is the centre of compound words. The heads of the compound nouns derived from the word carbon were classified into scientific terms, lexis of finance and accounting, a variety of lexical items, and religious words. In the scientific terms, it has a neutral sense. While in the other categories, both positive and negative senses can be found. 
The analysis of similar keywords in two corpora has been conducted by Fitzsimmons-Doolan (2009) to attest a belief that the language policy was influenced by immigration issues. The corpora have two different topics, i.e. language policy and immigration. There are only 6 percents keywords that appear in the corpora of language policy and immigration and no remarkable patterns were found. Therefore, immigration does not give much effect on language policy.

Another possible starting point is hapax legomena which is a word that only occurs once in a corpus (King, 2015). The hapax legomena in the chatrooms were categorized to see the purposes of communication. The main purpose is for socializing.

Establishing key semantic tag list can be the initial procedure in doing corpus-assisted discourse study. The words were categorized based on the USAS (UCREL Semantic Analysis System) to find the key semantic. Then, the words on the list were set up as the starting points (Sheryl, 2010). It compared the specialized corpus to reference corpus. It reveals what the strategies used in the texts to portray the issue of national identity on the texts discussing Scottish independence.

ConcGram is the other element that has been used in discourse analysis (Cheng \& Lam, 2012). In concGram, two words can co-occur with different variations of positions. Then, the collocates of the ConcGram were found. The collocates were classified to see semantic preference. Finally, semantic prosody was decided. They used this technique to examine how Western and Chinese media represented Hong Kong when it was handed over and ten years after that. There are some changes on how those media see the issue.

The studies discussed above used the principles of phraseology to examine specific discourse. Studying patterns in the previous studies focuses on the topics or the issues in the texts. The present study aims at exploring the way the writers established interaction in online reviews of tourist attractions by observing the keywords. This study enlarges the scope of studying the patterns in discourse by examining patterns in particular collocations. It also reveals how the writers position themselves and the readers. The previous studies have not deal with this issue.

\section{Method}

This study belongs to a corpus-assisted discourse study that covers quantitative and qualitative aspects. Considering quantitative aspects reduces researcher's subjectivity in analyzing. It was done by making lexis and patterns that were measured and judged as significant elements as the basis of analysis. The patterns build the discourse itself and each discourse has its own patterns that make it unique from the others. Furthermore, studying the patterns can reveal text structure, main ideas, or grammatical features that become the characteristics of the discourse.

The data was taken from a specialized corpus of 95,694 words. The texts in the corpus are online reviews taken from TripAdvisor website. It is a website where the writers can write the reviews of tourist attractions. The reviews were published on the website and can be read by everyone. The reviews were written 
in 2015-2016. The focus of the reviews is the tourist attractions in Lombok, Indonesia.

The study corpus was compared to a reference corpus which is Brown corpus by using Lextutor online to obtain the keywords. Brown corpus is a written corpus. Therefore, the study and reference corpora have the characteristics of written language. Keywords were chosen as the starting points of analysis because there is no assumption what the main topics in the corpus are. Therefore, obtaining keywords gives information about the main topics in the discourse. The keywords selected for analysis must fulfill three criteria. First, the keywords were the first-one hundred keywords. Second, the minimum frequency is 40 . Third, the keywords have at least 1 collocate and the minimum frequency of the collocation is 5. The collocates of the keywords are 4 words to the left and right.

Concordance studies of the keyword collocation and distinguished patterns were done to see how the writers interact and position themselves. The keywords and the collocates that are adjectives were classified through USAS (UCREL Semantic Analysis System) to know the senses of the words. The senses are positive, neutral, and negative. Some senses were marked with,+++ , or +++ to intensify the adjectives. The more symbol + that the word has, the stronger the sense is (Archer, 2002). In the concordance analysis, it is necessary to pay attention whether some words belong to same class of words such as pronouns, adjectives and adverbs to get more understanding of discourse (Feiz, 2014).

\section{Findings and Discussion}

Twenty one keywords were used as the basis of analysis. They appear in the base forms. The base forms might consist of several word types. Some keywords represent the objects such as waterfall and sand. Some keywords show the activities such as hike and climb. The following table shows the information about the word types.

Table 1: The keywords and their word types

\begin{tabular}{ll}
\hline Keywords & Word types \\
\hline waterfall & waterfall, waterfalls \\
trek & trek, treks, trekking \\
surf & surf, surfing \\
snorkel & snorkel, snorkeling, snorkelling \\
amaze & amazing \\
stun & stunning \\
hike & hike \\
rubbish & rubbish \\
turtle & turtle, turtles \\
beach & beach, beaches \\
swim & swim, swam, swimming \\
coral & coral, corals \\
Indonesia & Indonesia \\
guide & guide, guides, guided \\
sunset & sunset, sunsets \\
recommend & recommend, recommended \\
locate & located \\
\hline
\end{tabular}




\begin{tabular}{ll} 
summit & summit \\
sand & sand, sands \\
tour & tour, tours \\
climb & climb, climbing \\
\hline
\end{tabular}

on the concordance investigation of the keywords, there are several ways of writers' preferences in conveying their ideas in their reviews i.e. evaluating, giving advice and instruction, recounting, reporting, thanking, and encouraging to imagine. Evaluating covers both good and negative aspects of the objects. One of the ways is by using adjectives. Giving advice and instruction includes several topics and related issues that the writers concern. They do it based on their experiences. In this case, they showed that they are more knowledgeable than the readers. They tried to be the reliable sources of information by giving evidence. Narrating sequences of events that they did or what they observed becomes one part of their reviews. Another way to give information is by reporting. Reporting means the writers reported what others told to them. They give information from trusted sources to the readers. In the review, they did not only share knowledge and experiences but also emotions. It appears in expressions of gratitude. Thanking is writers' way to express their gratitude. In addition, the writers promoted the tourist attractions by encouraging the readers to imagine. In the next sub-sections, the patterns of language such as collocations and lexical bundles that were formed by using the keywords were described. They represent writers' way to interact.

\section{Evaluating}

Evaluating was done by modifying the objects with the adjectives. The adjectives are the collocates of the objects. There are 18 adjectives that function as the collocates of the keywords as can be seen in the table 2. The adjectives were checked in the USAS semantic categorization to know their senses. Ten out of eighteen adjectives have positive senses. One of the ten adjectives, best was marked with +++ . There are no adjectives with negative senses. The adjectives and the senses can be seen in Table 2 .

Table 2: The senses of the adjectives

\begin{tabular}{lll}
\hline Adjectives & Positive sense & Neutral sense \\
\hline nice & $\checkmark+$ & \\
beautiful & $\checkmark+$ & $\checkmark$ \\
worth & & \\
great & $\checkmark+$ & \\
good & $\checkmark+$ & \\
amazing & $\checkmark+$ & \\
stunning & $\checkmark+$ & \\
safe & $\checkmark+$ & \\
best & $\checkmark+++$ & \\
sharp & & \\
local & & \\
friendly & & $\checkmark$ \\
white & & $\checkmark$ \\
soft & & \\
\hline
\end{tabular}




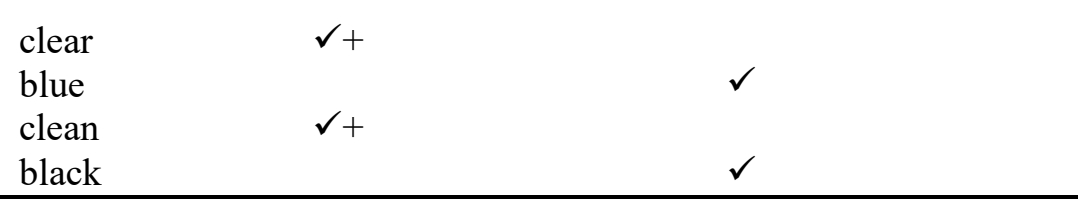

writers evaluated the objects by using the adjectives with positive sense such as nice, beautiful, and worth. The adjectives are the collocates of the objects evaluated. In several cases, they also used conjunctions that show contrary such as though, although, and but in the level of a sentence as can be seen in the following examples.

1. We quite stunning with the view as the waterfall keep their beautiful flow although it was raining at that time.

2. The next waterfall is nice, but the last one is amazing.

3. After enjoying the waterfall and the nice view, the 25 minutes walk uphill back to the meeting point was really tiring ... but worth it.

4. Beautiful waterfalls but surely not unique.

In example (1) the writers gave evaluation that carries positive sense towards the use of the word beautiful even though unexpected events occurred. They tried to ensure the readers that they enjoyed the trip. In examples (2), the writers contrasted the waterfall with others. The objects contrasted were evaluated by using positive senses (nice and amazing). In example (3), the writers evaluated and also encouraged the readers to try. In the example (4), the writer mentioned two characteristics, i.e. beautiful and not unique to give clear picture to the readers. From all examples, the writers tried to be factual by mentioning both positive and negative aspects of the objects.

Another way to evaluate is providing detailed information by mentioning several characteristics of the object of evaluation by using adjectives as in the following examples.

5. Our guide, Sultan, was friendly, warm, and definitely very experienced.

6. ... the guide is friendly, but not supportive ... .

There are 2-3 adjectives which were used to evaluate guides in each sentence. In the example (6), the writer used but to contrast two ideas. It also can be done by giving the details in preposition phrase with ... as in the examples below.

7. Clean white sand beach, with a near perfect, small, beginner surf break for those learning to surf.

The writer put himself as the one that knows a lot about the object in particular area as in the example (8) by mentioning in southeast Asia.

8. This is really worthy but really difficult trek in southeast Asia.

He created the image that he knows other treks in Southeast Asia. It is a strategy to convince the readers that what they told is true and the readers can trust them. It also occurs in the example (9). The writers gave detailed information about Maldives and Bora-Bora to prove that he has wide knowledge. Therefore, the readers can trust their evaluation. The phrase in the world increased the positive value of the object as can be seen bellow. 
9. One of the best diving/snorkeling in the world (I would rate as third after Maldives and Bora-Bora).

The occurrences of collocation of hike and but tend to appear with tough and worth as can be found in the concordance lines below.

10. The hike might be tough but it's totally worth it.

11. This was a tough hikebut the view at the top was worth it!

The writers told the truth that it was tough based on their experience did the hike. After that, they contrasted this condition with their impression at the end of the hiking. The use of the word tough might give impacts to the readers therefore the readers prepare all the necessary things for this tough trek. The use of the word worth shows they have positive attitude. This positive attitude might play a role as a supporting factor to encourage the readers to try.

Evaluating two or more objects in one sentence is also possible. Amazing tends to occur with beautiful at the sentence level as in the following sentences.

12. Amazing beach, just beautiful white sand, turquoise water.

13. It was an amazing adventure with beautiful mountain view.

One object was evaluated with the adjective amazing and the other one was evaluated with beautiful. Both adjectives have positive senses. The co-occurences of amazing and beautiful in one sentence makes the positive sense becomes stronger. The writers give positive portrayal to the readers.

The occurrences of perfect and great have been followed by prepositional phrases with for and to in order to give information as detailed as possible. In this case, the writers found the suitability. The writers expected the readers to get the best experience of visiting particular tourist attraction. They mentioned the most suitable activities. They do not want the readers to waste their time by missing the most suitable activities. Some of the examples can be seen below.

14. Great beach for those who want to learn how to surf ....

15. ... making a perfect place for a beginner to learn how to surf ... .

Writers' effort to find suitability of the objects can be found in the collocations of see and sunset that form to see sunset. Before these bundles, there is information about the place that shows the suitable point to see sunset. This is writer's attempt to be informative and make the readers get the best of it as in the following examples.

16. This is one of the best point to see sunset in Lombok.

17. For me this is the best place to see sunset with extraordinary view ....

Showing suitability can be realized through for and to as in the collocations of beach and great and beach and good. The writers tried to be detailed as in the examples below.

18. Great beach for paddling ....

19. This beach is so good to walk along ....

They presented suitability of the particular place and the activities. The suitability might include the issue of participants. It shows what kind of participants that are suitable for the place as in the following examples. 
20. The wave is quite small in this beach, making a perfect place for a beginner to learn how to surf ....

21. This beach is perfect for people that want to learn how to surf (beginners) ... Discussing objects might raise an issue that makes the readers worry. The writers realized it and tried to calm down by providing $b u t . .$. as in the following examples.

22. There is some dead coral at the beach but no problem.

23. You'll find more coral on the beach but it's not really an issue.

Anticipating specific conditions that the readers might face can be done by using if clause. Collocations of visit and worth and visit and place tend to appear with if clause as in the following examples.

24. Worth to visit if you don't have time to visit Tiu Kelep .... .

25. You must visit this place if you want to feel the warm weather ... .

\section{Giving advice and instruction}

A lexical feature that commonly used is recommend as can be seen in the examples below.

26. Thank trekking company "DEWELL trekker" for his team were very nice and we would recommend at a friend ...

27. We highly recommend this hike as the views are spectacular!

28. I would definitely recommend Gilli Air rather than .... .

29. It's totally recommended to visit and come ... .

Adverbs highly, definitely, and totally in examples strengthen the recommendation. Before giving recommendation, the writer in example (26) thank the trekking company. It reveals writers' satisfaction. For his satisfaction, he gave recommendation. The writer also gave a reason when giving advice as in example (26). Comparing also happens in example (28).

Using modals i.e. should, can, must, and need is another way to give advice. Need might appear in the negative sentences. The following are the examples.

30. You should have a tour guide to have the story behind ... .

31. If you want to see the sunset, you must be at that beach around $5.30 \mathrm{pm}$.

32. You need to have local guide to get in .... .

33. Although there is no need to have a guide, you can hire a guide just before the entrance who can carry your luggage and toddler.

The occurrence of the phrase no need before the clause you can hire ... in the example (31) shows that it is only an advice. There is no obligation. In some sentences, the writers stated the purposes after giving advice through the realization of to clause as in examples (30) and (32).

Some advice tends to be a command as it occurs in imperative sentences as in the following examples.

34. There is some dead coral and rocks so best wear booties ... .

35. But take a local guide, because they can explain very well the history of this village ....

36. Get a tour guide.

37. ... I suggest you abandon your shoes, try some snorkeling or diving in the turtle ....

Making sure that their advice is a way to get the most comfortable experience, the writer used the word best as in example (34). To prove that their advice is reasonable, the writers mentioned the reason in example (35). To soften the 
command, the writer used I suggest ... before the imperative clause such as in example (37).

Giving particular conditions by using if you before giving advice and command is writers' attempt to provide the suitability as in the examples below.

38. If you are beach lover, you have to visit this beautiful beach.

39. If you want a beach holiday, stay in Bali.

From the way the writers address the readers directly by using you, the writers consider issues related to the readers seriously.

\section{Reporting}

Reporting what the others said becomes the writer's concern. The writers shared any information that they got from the guides. The writer contrasted what the guide told and what they saw. It enriches the information to the readers. Reporting can be seen in the examples below.

40. Our guide said everyone weaved in their houses but we looked in the houses and didn't see any anywhere!

41. Our guide said many accidents happen there ....

\section{Recounting}

The writers told their stories. They mostly play roles as the actors. It was shown by the use of subject $I$ and we. The writers mentioned the purposes by using to infinitive and used some linking words i.e. and and after (examples 42 and 43) to connect two events. After also shows the sequence of events. Another possibility to act as the actor is guide because guide is a person who accompanies them (example 44). The writers observed the surroundings including what other people did (example 45). It was used in relation to evaluate the tourist attraction (beach). The writers act as the story tellers that told every important events and persons in the journeys as in the following examples.

42. We took the island hopping snorkeling and went to see the corals.

43. After doing trekking program, my guide took me to explore this waterfall.

44. Our guide simply took us along the path.

45. It is clean and they always clean the beach ....

Telling what the writers did might inspire the readers what should be done in the tourist attractions. Providing the sequences of activities might give portrayal to the readers about the rundown of the trips. The readers might follow what the writers did.

\section{Thanking}

Thanking shows writers' attitudes. The writers mentioned specifically the persons to whom they thanked to emphasize the roles of the persons in their trips as in the following examples.

46. Special thanks to our guide and the porters ....

47. My great thanks to guide Ary trekking once again Ary thank Ary trekking.

48. Thank trekking company "DEWELL trekker" for his team were very nice ... .

The use of adjectives special and great represents how thankful they are (examples 46 and 47). Specific reason of thanking was given in example (48).

Writers' enjoyable experiences can be separated from the help of those persons. The writers indirectly promoted them to the readers. It is also seen as their ways to make the readers get the best experience. 


\section{Encouraging to imagine}

The writers encouraged the readers to imagine what they will experience in their visit based on their experiences. The phrase you will were used to mention possible activities to be done by the readers. It also gives ideas to the readers what they will do in the tourist attractions. Using if you makes them as active participants that shows they have positions in the reviews. The reviews are not only about the writers and their experiences but it is also about the readers as the prospective tourists. The readers are not the passive outsiders that listen to the stories. The examples below show how the readers were involved.

49. ... a local guide will welcome and offer you a tour of the village.

50. You will see a lot of turtles.

Feeling that what they read is about their own experiences will make them keep reading the reviews.

\section{Conclusion}

In interaction, the writers evaluated, gave advice and instructions, reported, recounted, thanked, and encouraged to imagine. The keywords tend to collocate with particular word(s) or phrase(s) that build particular meanings and language functions. Some adjectives as collocates carry positive senses. Even, some contain stronger positive senses that influence the meaning in the discourse.

Contrastive conjunctions, time connectives, prepositional phrases with, for, and to, if clause and to clause becomes the features of the texts. The writers used these structures to convey their ideas to help the readers. They gave their best effort to be as informative as possible. A number of detailed information was given to the readers to help them make choices, get the best experiences, and anticipate situations. Getting trust from the readers is done by mentioning the facts whether they are positive and negative aspects and giving reasons when they gave advice. Interaction with the readers was built by addressing them directly, especially in the phrase if you. The writers were involved in this aspect and their suitability and enjoyment were considered.

This study is restricted on the analysis of online reviews of tourist attractions. Further studies can use other types of online reviews such as movie reviews to see whether similar features can be found. The study gives contribution to the field of the internet-based communication. It gives a description of language use and characteristics of interaction in online reviews. Writing a review is not only about examining objects. It is intended to help the readers make decisions.

\section{References}

Anthony, L. (2014). AntConc (Version 3.4.3) [Computer Software]. Tokyo, Japan: Waseda University. Available from http://www.laurenceanthony.net/

Archer, D., Wilson, A., \& Rayson, P. (2002). Introduction to the USAS category system. Retrieved from http://ucrel.lancs.ac.uk/usas/usas_guide.pdf

Baker, P. (2004). Querying Keywords: Questions of difference, frequency, and sense in keywords analysis. Journal of English Linguistics, 32(4), 346-359. doi: $10.1177 / 0075424204269894$ 
Baker, P., Gabrielatos, P., Khosravinik, M., Krzyzanowski, M., McEnery, T., \& Wodak, R. A. (2008). Useful methodological synergy? Combining critical discourse analysis and corpus linguistics to examine discourses of refugees and asylum seekers in the UK press. Discourse \& Society, 19(3), 273-306. $10.1177 / 0957926508088962$

Cheng, W. \& Lam, P. W.Y. (2012). Western perceptions of Hong Kong ten years on: A corpus-driven critical discourse analysis. Applied Linguistics, 34(2), 173-190. doi: 10.1093/applin/ams038

Cobb, T. [Keywords Extractor] Accessed on 20 October 2016 at http:// http://www.lextutor.ca/key/

Fitzsimmons-Doolan, S. (2009). Is public discourse about language policy really public discourse about immigration? A corpus-based study. Language Policy, 8, 377-402. doi: 10.1007/s10993-009-9147-6

Gee, J. (2011). An introduction to discourse analysis: Theory and method. New York: Routledge.

Hamilton, C., Adolphs. S., \& Nerlich, B. (2007). The meaning of 'risk': A view from corpus linguistics. Discourse \& Society 18(2), 163-181. doi: 10.1177/0957926507073374

Jaworska, S. \& Krishnamurthy, R. (2012). On the F word: A corpus-based analysis of the media representation of feminism in British and German press discourse, 1990-2009. Discourse \& Society, 23(4), 401-431. doi: $10.1177 / 0957926512441113$

King, B.W. (2015). Investigating digital sex talk practices: A reflection on corpusassisted discourse analysis. In R. H. Jones, A. Chick, \& C. A. Hafner (Eds.), Discourse and digital practices: Doing discourse analysis in the digital age (pp. 130-143). Abingdon: Routledge.

Koteyko, N. (2012). Mining the internet for linguistic and social data: An analysis of "carbon compounds" in web feeds. Discourse \& Society, 21(6), 655674. doi: 10.4135/9781446268513.n73

Lirola, M. (2014). The portrayal of women's contribution to Irish society through a sample from the Irish press. Studi Irlandesi, 53-68. doi: 10.13128/SIJIS2239-3978-14667

Partington, A., Duguid, A., \& Taylor, C. (2013). Patterns and meanings in discourse: Theory and practice in corpus-assisted discourse study (CADS). Amsterdam: John Benjamins.

Strauss, S. \& Feiz, P. (2014). Discourse analysis: Putting our worlds into words. New York: Routledge.

Scott, M. \& Tribble, C. (2006). Textual Patterns: Key words and corpus analysis in language education. Amsterdam: John Benjamins.

Sheryl, P. (2010). Using automated semantic tagging in critical discourse analysis: A case study on Scottish independence from a Scottish independence from a Scottish nationalist perspective. Discourse and society 21(4), 405-437. doi: $10.1177 / 0957926510366198$

UCREL Semantic Analysis System (USAS). (n.d.). Retrieved on 25 October 2016 from http://ucrel.lancs.ac.uk/usas/tagger.html. 